\title{
The concepts of surveillance and sousveillance - a critical analysis
}

Frej Klem Thomsen, Senior Researcher, Danish Institute of Human Rights, fret@humanrights.dk

July 2019 draft

\begin{abstract}
The concept of surveillance has recently been complimented by the concept of sousveillance. Neither term, however, has been rigorously defined, and it is particularly unclear how to understand and delimit sousveillance. This article sketches a generic definition of surveillance and proceeds to explore various ways in which we might define sousveillance, including power differentials, surreptitiousness, control, reciprocity, and moral valence. It argues that for each of these ways of defining it, sousveillance either fails to be distinct from surveillance or to provide a generally useful concept. As such, the article concludes that academics should avoid the neologism, and simply clarify what sense of surveillance is at stake when necessary.
\end{abstract}

Surveillance is a topic that has attracted increasing scholarly attention over the past decade - in academia more generally and in philosophy in particular. (Sorell 2011, Macnish 2014, Milaj 2015, Hadjimatheou 2016, Macnish 2016) Recent years have seen the development of the related concept of "sousveillance", often loosely defined as "reverse surveillance" or "surveillance from below". Although sousveillance has been adopted and employed both in public debate and in the academic literature, it is unclear exactly how we ought understand it, and how it differs from surveillance.

This article explores the concepts of surveillance and sousveillance, argues for a definition of the former, and presents a series of problems that candidate definitions for the latter encounter. It concludes that there is no obvious way of picking out a separate concept of sousveillance. As such, despite the rhetorical appeal of employing as sexy sounding a concept as "sousveillance", it is probably preferable to simply speak of varieties of surveillance.

\section{Sousveillance in the literature}

The term "sousveillance" can be traced to a 2003 article by Steve Mann, Jason Nolan and Barry Wellman, in which these scholars report their experiments with employing wearable videorecording devices and using these to project the recordings in public spaces or to record facilities and employees of stores that themselves record customers. (Mann, Nolan et al. 2003) Mann and colleagues label these activities, which deliberately draw attention to the fact of the recording and "record the recorders", sousveillance and claim that they are distinct from and opposed to conventional surveillance.

Unfortunately, Mann et al make scant attempts to define their neologism. The closest they come to a definition is the invocation, in the introductory part of the article, of a contrast with conventional forms of monitoring and observation:

\footnotetext{
"All such activity has been surveillance: organizations observing people. One way to challenge and problematize both surveillance and acquiescence to it is to resituate these technologies of control on individuals, offering panoptic
} 
technologies to help them observe those in authority. We call this inverse panopticon "sousveillance"..." (Mann, Nolan et al. 2003)

In addition to this, they later provide a list of what they take to be examples of sousveillance:

"[C] ustomers photographing shopkeepers; taxi passengers photographing cab drivers; citizens photographing police officers who come to their doors; civilians photographing government officials; residents beaming satellite shots of occupying troops onto the Internet." (Mann, Nolan et al. 2003)

Even if we accept these examples, however, the question remains what unifies them as examples of a distinct concept.

More recent articles that employ the concept take a similarly unclear approach. Meg Stalcup and Charles Hahn suggest that:

"Rather than the overview position of surveillance, [sousveillance] was watching from "below" [...], including people recording and posting their encounters with police." (Stalcup and Hahn 2016)

In a similar vein, Jean-Gabriel Ganascia devotes a section to defining sousveillance, but does not get much closer than the claim that:

"In the case of sousveillance, the watchers are socially below those who are watched, while in the case of surveillance it is the opposite, they are above." (Ganascia 2010)

In a claim with a somewhat wider scope, Jean-Gabriel Ganascia writes that:

"Surveillance societies were centralized, based on a hierarchical social structure, and localized in a physical building. By contrast, the generalized sousveillance society is equally distributed, strictly egalitarian and delocalized over the entire planet." (Ganascia 2010)

Finally, Dawn Freshwater, Pamela Fisher and Elizabeth Walsh also tie their definition to the idea that:

"...sous is the French term meaning below; in other words, the control is no longer with the eye in the sky but involves relocating surveillance within society within more mundane and democratic forms of observation. The aim is to subvert the gaze of the Panopticon." (Freshwater, Fisher et al. 2015)

Although there is something intuitive to the idea that sousveillance is "bottom-up" as opposed to "top-down", or that it is a kind of "reverse surveillance" these notions are not by themselves sufficiently precise to establish a clear understanding of sousveillance. We will have to go a little deeper. 


\section{Defining surveillance}

One place to start is with a definition of surveillance. After all, sousveillance is intended to be a related concept, and as such will share some conditions with surveillance although it must differ with respect to others. Surveillance, however, is itself not a well-defined concept. In one recent article Ross Bellaby writes that:

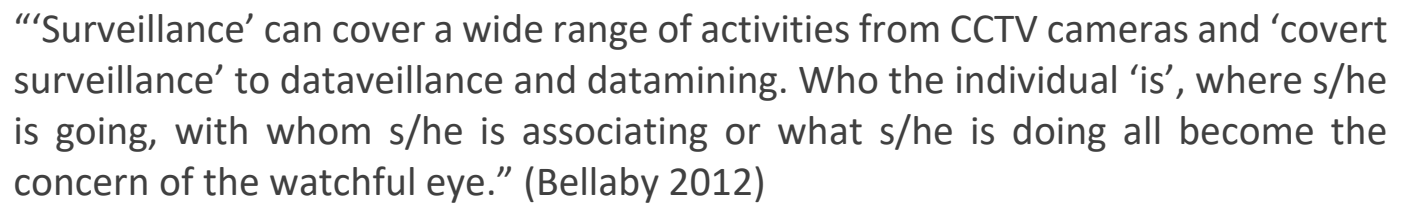

This is on the right track, but not intended as a definition, and too loose if read as one: we need to know what unifies these activities so as so make them instances of a common concept.

On the other hand, we must not narrow the scope too much. David Lyon suggests that surveillance is "any collection and processing of personal data, whether identifiable or not, for the purposes of influencing or managing those whose data have been garnered." (Lyon 2001) As Kevin Macnish observes, this excludes too much, both in requiring the specific purposes of influencing or managing, and in requiring surveillance to collect data. We should presumably allow for surveillance in cases of e.g. voyeuristic interest, and attempted but unsuccessful data collection. (Macnish 2017)

Macnish himself has provided several useful informal definitions of surveillance. In an encyclopaedia entry on the topic, he writes that:
"Surveillance involves paying close and sustained attention to another person. It is distinct from casual yet focused people-watching, such as might occur at a pavement cafe, to the extent that it is sustained over time. Furthermore the design is not to pay attention to just anyone, but to pay attention to some entity (a person or group) in particular and for a particular reason. Nor does surveillance have to involve watching. It may also involve listening, as when a telephone conversation is bugged, or even smelling, as in the case of dogs trained to discover drugs, or hardware which is able to discover explosives at a distance." (Macnish)

In another recent article Macnish writes: "I use "surveillance" here to mean the monitoring of a competent adult or adults over a period of time without their consent." (Macnish 2015) Finally, in his "The Ethics of Surveillance", Macnish recognizes the difficulties of defining surveillance, but adopts "for the purposes of [the] book" the understanding that surveillance is "the sustained monitoring of a person or people". (Macnish 2017) Both of these definitions are explicitly stipulatory - they are intended only to provide a definition suitable for a particular purpose. Can we build on their observations, to set out a precise general definition?

I think we can say, as a relatively satisfactory generic definition of personal surveillance, that an agent $A$ engages in surveillance against person(s) $P$ iff:

1) A performs an observation (or a series of observations) $\varphi$ of $P$.

2) $\Phi^{\prime}$ ing is (or is intended to be) sufficiently extensive.

3) $\Phi^{\prime}$ ing is intended to obtain information I about $P$. 


\section{4) $\Phi^{\prime}$ ing is suitable for obtaining I.}

The definition merits seven points of motivation and clarification. First, the surveillance at stake is personal because it targets persons, as opposed e.g. to spaces, phenomena, or objects other than persons. ${ }^{1}$ (cf. Macnish 2017) On the other hand, the definition deliberately leaves the nature of the agent open, so as to allow e.g. institutions, CCTV networks, or software algorithms to qualify. It is also compatible, of course, with the definition that the agent and the target are identical, such that a person subjects herself to surveillance, e.g. by wearing and periodically checking a biometric recording device to monitor heart-rate or insulin levels.

Second, whether we ought to describe such surveillance as one action or as a series of connected actions depends on the complex issue of how to individuate actions. Consider an agent who shadows a person several days in a row: is this one action of surveilling the target, or a series of consecutive acts of surveillance? I do not think that for the purposes of this definition anything important hinges on whether we opt for one or the other, so I allow both options.

Third, we are required to be more demanding with respect to how we understand 'observation' in the definition. Fundamentally, surveillance concerns gathering information about a target, but as both Bellaby and Macnish emphasize, it can take a number of forms, so 'observation' must be interpreted liberally enough to include not only looking at or listening to a person, but also e.g. tracking her location via GPS, scanning electrical, radioactive and chemical activity in her house, or data-mining her activities online. ${ }^{2}$ On the other hand, "observation" is intended to rule out certain actions that gather information in ways that intuitively do not count as surveillance. Crucially, the information must not be communicated to the agent by the target (or another person), which we would ordinarily label interviewing or interrogating rather than surveilling. ${ }^{3}$ Furthermore, the act of observation must have a relatively tight chronological connection to the causal origin of the information. The modern historian who reads Otto von Bismarck's correspondence does not qualify as engaged in surveillance, but the NSA spy who reads the present German chancellor's does.

Fourth, condition 2) restricts the concept of surveillance so as to avoid including trivial forms of observation. Consider a person who briefly glances at a fellow passenger in a train to examine her pretty scarf. This observation is too fleeting for it to count as surveillance. However, if the person performed daily observations on the train of what clothes this particular fellow passenger was wearing, we might be willing to say that she performed a form of surveillance. ${ }^{4}$ Note however, that it is the act of surveilling $(\varphi)$ that must be sufficiently extensive, not the information obtained that must be sufficiently wide or deep. Indeed, otherwise suitable observations presumably still qualify

\footnotetext{
${ }^{1}$ It is clearly possible for a single action to constitute surveillance in both an impersonal and personal sense. A fixed position CCTV camera surveils the space within its view, but it also surveils any person who occupies that space, from they enter to they leave.

2 Macnish prefers "monitoring" to "observing". I prefer the latter, in the admittedly atypical liberal sense set out above, for the purely pragmatic reason that I refer often to agents "performing an observation", which becomes somewhat clumsy if rephrased as an agent "performing a monitoring". I do not think there are any substantial differences between what I mean by "sufficiently extensive observations" and what Macnish means by "monitoring".

3 I take "communicating to a person" to be intentional and dialogical in a way that making a statement that is eavesdropped upon is not. Clearly, the latter can qualify as an instance of surveillance.

${ }^{4}$ Some might prefer to label her actions a (minor) form of stalking, but I take this to be compatible with my claim, since stalking seems to be (or to involve) a kind of surveillance.
} 
as surveillance even if they fail to uncover any information, e.g. because the target has been alerted and thwarts the operation. Surveillance may differ in important respects depending on the amount and type of information uncovered, but this is arguably better conceived as different consequences of surveillance than as a difference constitutive of whether an action is or is not surveillance in the first place. Furthermore, we may want to qualify the requirement so as to include cases where the observation is unexpectedly interrupted so long as it was intended to be sufficiently extensive. It seems to me that we could say e.g. that officers bugging a criminal's house have at least begun surveillance, even if the operation is suddenly aborted after working for only a few minutes. Finally, the question of what qualifies as sufficiently extensive is difficult to answer. I suspect that surveillance may be vague along this dimension, so that there is no definite threshold for sufficiently extensive observations, but I do not think this is inherently problematic. Such vagueness more plausibly simply reflects the fact that our concept of surveillance has blurry boundaries.

Fifth, condition 3) requires that surveillance is intentional because information gathering that occurs by accidental observations does not seem to qualify as surveillance. In order to constitute surveillance of $P$, the agent must perform the observations in order to obtain certain information about $P$. The intentionality required is minimal, however. Crucially, the definition does not require that gathering the information must be an end in itself. Gathering information may be, and realistically mostly will be, a means to some other end. That is, while the agent must intentionally observe the target for the action to qualify as surveillance, she can do so with any conceivable underlying intention or combination of intentions. Note also that I take no stand on the moral relevance of this intentionality. An otherwise identical unintentional observation may be morally identical to surveillance, e.g. with respect to permissibility, or it may not. Views on this point will divide along familiar lines between consequentialists and deontologists. My point here is merely that the unintentional observation does not seem to conceptually qualify as surveillance.

Sixth, condition 4) rules out forms of pseudo-surveillance that are not suitable for obtaining information, such as laying the target's horoscope or gazing in a crystal ball. We might instead further restrict the concept of "observation" to apply only to such suitable methods, but it does no harm and may avoid some confusion to spell out the condition here.

Seventh, and last, the definition of surveillance I have set out is strictly descriptive. A moralized conception of surveillance would hold that something is an instance of surveillance only if it is in some respect morally objectionable. Here I agree with Macnish, that:

\footnotetext{
"Surveillance is itself an ethically neutral concept. What determines the ethical nature of a particular instance of surveillance will be the considerations which follow, such as justified cause, the means employed, and questions of proportionality." (Macnish)
}

The descriptive definition is consistent with all instances of surveillance actually being morally bad, because moral badness is entailed by one or more of the properties that define something as an instance of surveillance, it merely denies that it is conceptually true of surveillance that it is morally bad. 


\section{A first attempt at sousveillance - a power differential}

If we accept the above account as (roughly) adequate for what we mean by surveillance, it may appear tempting to define sousveillance by simply adding a further condition to capture the notion of "surveillance from below". It is worth bearing in mind, however, that the authors who employ the concept of sousveillance clearly take sur- and sousveillance to be binary - that is, for sousveillance to constitute an alternative to rather than a subclass of surveillance. This affects the plausibility of candidate conditions: if they end up including examples of what we intuitively want to label surveillance, then they do not satisfactorily pick out sousveillance.

What might the condition of sousveillance be? A good candidate appears to be the relation of power, since this is explicitly or implicitly at the centre of the definitions we found in the literature, such that agent stands in a relation of inferior power to the target (and the opposite in conventional forms of surveillance). Consider then a power differential-based account of sousveillance, which holds that an agent $A$ engages in sousveillance against persons $P$ iff:

1) A performs an observation (or a series of observations) $\varphi$ of $P$.

2) $\Phi^{\prime}$ ing is intended to obtain information I about P.

3) $\Phi^{\prime}$ ing is suitable for obtaining $\mathrm{l}$.

4) $\Phi^{\prime}$ ing is sufficiently extensive.

5) A stands in a relation of inferior power to $P$.

There are several difficulties here. The first is that power is not a precise concept, and it is not clear what sense might be at stake in sousveillance. ${ }^{5}$ Is $P$ superior in power when she is wealthier than $A$ ? Physically stronger? Has higher social status? Enjoys the legal ability to (in some way) harm $A$ without fear of reciprocation? Is psychologically capable of dominating $A$ ? Has more information about $A$, or better opportunities for gathering information about $A$, than the reverse? All (or some) of the above? The concept of sousveillance will look quite different depending on which sense of power is at stake.

A different problem is that there will presumably be a lower bound for the power differential to count - very few persons are exactly equally powerful, and it seems odd to allow the trivial differences in power found among ordinary persons to alter their actions from sur- to sousveillance (and vice versa). If this observation is correct, then there must be a sufficiently large power differential between the person for something to qualify as sousveillance, but it strikes me as difficult to establish where this threshold might be. ${ }^{6}$

The third and most serious problem is that no matter how one responds to the issues mentioned above, the power differential-based account of sousveillance appears to be vulnerable to strong counterexamples. Consider three cases:

\footnotetext{
${ }^{5}$ As so often, the Stanford Encyclopedia of Philosophy provides an excellent overview of the positions in and complexity of the literature. see the "Definitions of power"-section in the article on "Feminist Perspectives on Power". Allen, A. (2016). Feminist Perspectives on Power. Stanford Encyclopedia of Philosophy. E. N. Zalta.

${ }^{6}$ A related issue - what do we call exactly or sufficiently equal persons gathering information about each other in the requisite sense? "Interveillance"? Or are these species of surveillance? I set these questions aside here, however.
} 
Tinker Tailor. During the Cold War, an isolated Swedish intelligence agent in Moscow shadows a group of KGB agents.

Paparazzi. A poor, socially isolated immigrant stakes out the holiday location of a wealthy, well-connected Hollywood celebrity, hoping to take photos of the celebrity, and sell these to tabloid media.

Corp-Sec. A small farmer installs cameras that record facilities and equipment, in order to protect against sabotage committed by agents of a vast farming conglomerate, which has already consumed the neighbouring farms, and is pressuring the farmer to sell.

Intuitively, all three cases seem to involve surveillance - indeed, they are fairly paradigmatic cases of surveillance. However, on any plausible version of the power differential at stake in sousveillance, at least one, and likely more than one, of the cases concerns an agent performing observations against a substantially more powerful target.

If sousveillance is not merely a subspecies of surveillance (so that something cannot be at once a case of the former and of the latter), then this means that a power differential is not sufficient to single out cases of sousveillance. Let us look briefly at five alternative suggestions: that there is a distinction in openness, in control, in reciprocity, in institutional status, and in moral valence.

\section{Surreptitious and open observation}

Another suggestion at least hinted at in the literature is that sousveillance is open and undisguised, while surveillance must then be surreptitious:

“...the original notion of sousveillance promoted by Steve Mann signifies that every watcher would voluntarily give free access to all information recorded. Usually, people recording information take part in the event and participants are aware of the recording." (Ganascia 2010)

A candidate for this condition might be:

$5^{*}$ ) The observation is carried out openly, such that P is or easily could become aware of being observed.

Clearly, however, this will not work. The public CCTV systems that have attracted such heated debate over the past decade are no less surveillance for the fact that they are disclosed or even advertised, nor would it intuitively affect the nature of the farmer's actions in Corp-Sec whether he hides the cameras or leaves them in out in the open.

\section{Public and private control of information}

A different suggestion might be that the distinction concerns control of the resulting information if it is or will be in the hands of a private individual or organization, then the acts constitute surveillance, whereas if it is publicly available, then the acts constitute sousveillance. Ganascia seems to think that the information being publicly available is at least one feature that can characterize sousveillance: 
"Here, the concept of sousveillance has been generalized to include individuals sharing personal data and anonymous records generated by automatic devices, i.e. security camera systems, video surveillance, CCTV, etc." (Ganascia 2010)

A candidate for this condition might be:

$\left.5^{* *}\right)$ The information obtained through observation is made available to the public.

The trouble is again that the distinction fails to rule out plausible cases of surveillance. The whole point of surveillance in Paparazzi is to take photos that can be publicly disseminated in tabloid media, but the case seems to constitute surveillance regardless.

\section{Reciprocal observation}

Another suggestion is that sousveillance is reciprocal, that is, sousveillance is observations conducted against persons who are similarly observing the agent:

"The idea here is that the watched can record the actions of the watcher, for example with the purpose of making this information public." (Vertegaal and Shell 2008)

A candidate for this condition might be:

$\left.5^{* * *}\right) \mathrm{A}$ is herself the target of sufficiently sustained, intentional, informationgathering observations by $P$.

There are at least three reasons to think this is not the right distinction. First, in at least some cases this seems to make sousveillance simply a form of transparency - presumably proponents of the concept of sousveillance intend for it to mean something else, since otherwise there would have been no need to introduce the term. Second, it would include at least some cases of what we would prefer to label surveillance, such as a variant of Tinker Tailor where the KGB is simultaneously monitoring the Swedish agent. Third, it appears to rule out paradigm cases of what proponents take sousveillance to be, such as a civilian bystander discretely filming police officers violently arresting an innocent person with her cellphone camera.

\section{Individual and institutional observation}

Let us consider finally two proposals that, so far as I can tell, are not suggested in the literature, but which might nonetheless be thought to capture the distinction. The first is that there is a difference between the sousveillance carried out by private individuals and the surveillance carried out by institutions or agents acting on behalf of institutions.

A candidate for this condition might be:

$$
5 * * * *) \mathrm{A} \text { is an institution or the agent of an institution. }
$$

An important difficulty for this condition is that it requires us to be able to say when an agent is in the relevant sense an institution or an agent of an institution. There are uncontroversial cases - the police is an institution, and individual police officers are agents of that institution - but also unclear 
cases. Is the immigrant photographer in Paparazzi an agent of an institution? Is the CCTV-protected cornershop an institution? If not, what about the chain of such cornershops? A more pressing problem however is that, as with the other suggestions we have reviewed so far, it appears to draw the distinction in the wrong place with respect to intuitive cases. Consider:

Stalker. Erotomaniac spends her time compulsively monitoring the doings of Victim. She follows Victim around, taking photos of her, tracks her life on social media, and uses binoculars and a laser-microphone to snoop through Victim's windows.

Presumably Erotomaniac is performing a kind of surveillance, but clearly she is neither an institution or the agent of an institution. The individual-institutional distinction therefore fails. ${ }^{7}$

\section{Morally different observations}

The final suggestion I want to consider is the idea that there is a difference in moral valence. We must be careful to distinguish two version of this idea. We might on the one hand think that there is a (non-moral) difference between surveillance and sousveillance which makes a moral difference. If, for example, surveillance is those in power observing the governed while sousveillance is the governed observing their oppressors, then this might be thought to make a difference to the moral status of the actions. On the other hand, we might think that the difference between surveillance and sousveillance just is the moral difference, that is, that otherwise similar acts of observation become either sousveillance or surveillance depending on the moral status of the act.

The difficulty for the first approach - where a difference between surveillance and sousveillance makes the two morally different - is that it requires us to be able to distinguish the two on some other grounds, such as those discussed above, and then explain why this distinction is morally relevant. Thus, the example above of a difference between observations by those in power of the governed, and those governed of those in power, is really just a restatement of the idea that surveillance and sousveillance can be distinguished on the basis of the power relationship between the agent and the target. As we saw initially, this distinction does not work.

This leaves the second approach, of saying that an act becomes either surveillance or sousveillance depending on the its moral valence. A candidate for this condition might be:

$$
5 * * * *) \text { ('ing is morally good. }{ }^{8}
$$

While this condition might appear to capture at least some of what differentiates cases of supposed sousveillance and surveillance - corporations snooping on the emails of their employees is bad surveillance, citizens filming police abuse of powers is good sousveillance - it too fails to fit strongly intuitive cases.

\footnotetext{
${ }^{7}$ As I noted above (fn.4) I take stalking to be or to involve a kind of surveillance, so it is no objection to Stalker to insist that we should label Erotomaniac's actions stalking.

${ }^{8}$ This implies that surveillance is morally bad. Obviously we can imagine drawing the line at other places in normative space, e.g. more ambitiously between permissibility and impermissibility, or more modestly between being valuable and disvaluable. It does not seem to me that it will make a difference exactly where it is drawn, however, since any plausible normative distinction will run into the problems I set out below, or closely related versions of them.
} 
Consider:

Speedsters united: A group of motorists take photos using their cellphones whenever they pass a mobile traffic speed camera and upload the photos to a group on social media. This allows other members to avoid being caught speeding at this location. ${ }^{9}$

The purpose of mobile traffic cameras is to create a deterrent threat against speeding. ${ }^{10}$ Supposing plausibly that speed limits benefit society, that is, it imposes more costs than benefits when drivers exceed speed limits, the information-gathering observations of the speedsters that undermine this deterrent threat imposes a cost on society. In short, this looks a lot like what proponents would want to call sousveillance, but of a morally bad kind. To make matters worse, it seems obvious that many forms of what we conventionally label surveillance are morally good. Police surveillance of organized crime which serves to prevent extortion, drug distribution and murder, is just one clear example. (cf. Macnish 2017) The distinction cannot rest on a moral difference. ${ }^{11}$

\section{Conclusion}

Over the course of this article I have reviewed the use and existing definitions of sousveillance, showing that the concept stands in need of clarification. I have presented a definition of generic personal surveillance, some conditions of which sousveillance will presumably share. I then reviewed a total of six conditions that could potentially distinguish it. I have argued that none of these draw a credible distinction between the cases proponents of sousveillance take to exemplify it and conventional cases of surveillance. My tentative conclusion is that there is no clear distinction between what proponents label sousveillance and conventional surveillance. It is tentative only because it is always possible that proponents will be able to point to a distinction which I have failed to consider.

Given this skeptical conclusion, it does not seem to me that anything of importance will be lost, and both clarity and simplicity appear to be gained, if we speak e.g. of civilians performing surveillance against their governments, or citizens performing surveillance against corporations, rather than of sousveillance.

Academic jargon comes at a cost. This cost is most obviously the required efforts on behalf of the reader to learn the jargon, but also the obscurity of the text to those who have not or cannot make such efforts. Because it imposes this cost, jargon should be employed only when doing so provides a tangible benefit. This is often the case. Jargon allows conciseness. An academic text can say more

\footnotetext{
${ }^{9}$ More sophisticated surveillance technologies that serve a similar purpose are becoming common. For obscure reasons (I do not drive a car), I receive an inordinate amount of advertisements on social media for a technology that combines a smart-phone app and a Bluetooth device, which jointly allows the network of users to register and warn each other of the presence of mobile traffic speed cameras.

${ }^{10}$ A Cochrane-review of the evidence of the effect of traffic-cameras concludes that they have significant deterrent effects. Wilson, C., C. Willis, J. K. Hendrikz, R. Le Brocque and N. Bellamy (2010). "Speed cameras for the prevention of road traffic injuries and deaths." Cochrane Database Syst Rev(11): Cd004607.

${ }^{11}$ Could we insist on the moral distinction as a revisionary concept of sousveillance? We might, but at the cost of at once diverging from how proponents of sousveillance appear to have employed the term, and of making it superfluous. After all, we can simply speak of morally good and morally bad surveillance, with no need for a revisionary and potentially confusing neologism.
} 
in fewer words, with a higher degree of precision, by employing specialized terms with rigorously defined meanings. However, as much fun as it is to coin a new term and employ it, academics should resist the temptation to do so when it obscures more than it elucidates. If my analysis of the concept of sousveillance above is correct, then it is time scholars simply stop using it.

\section{References}

Allen, A. (2016). Feminist Perspectives on Power. Stanford Encyclopedia of Philosophy. E. N. Zalta.

Bellaby, R. (2012). "What's the Harm? The Ethics of Intelligence Collection." Intelligence and National Security 27(1): 93-117.

Freshwater, D., P. Fisher and E. Walsh (2015). "Revisiting the Panopticon: professional regulation, surveillance and sousveillance." Nursing Inquiry 22(1): 3-12.

Ganascia, J.-G. (2010). "The generalized sousveillance society." Social Science Information 49(3): 489-507.

Hadjimatheou, K. (2016). "Surveillance Technologies, Wrongful Criminalisation, and the Presumption of Innocence." Philosophy \& Technology: 1-16.

Lyon, D. (2001). Surveillance Society: Monitoring everyday life. Buckingham, Open University Press.

Macnish, K. Surveillance Ethics. The Internet Encyclopedia of Philosophy.

Macnish, K. (2014). "Just Surveillance? Towards a Normative Theory of Surveillance." Surveillance \& Society 12(1): 142-153.

Macnish, K. (2015). "An Eye for an Eye: Proportionality and Surveillance." Ethical Theory and Moral Practice 18(3): 529-548.

Macnish, K. (2016). "Government Surveillance and Why Defining Privacy Matters in a Post-Snowden World." Journal of Applied Philosophy 33(3).

Macnish, K. (2017). The Ethics of Surveillance: An Introduction, Routledge.

Mann, S., J. Nolan and B. Wellman (2003). "Sousveillance: Inventing and Using Wearable Computing Devices for Data Collection in Surveillance Environments." Surveillance \& Society 1(3): 331-355.

Milaj, J. (2015). "Privacy, surveillance, and the proportionality principle: The need for a method of assessing privacy implications of technologies used for surveillance." International Review of Law, Computers \& Technology: 1-16.

Sorell, T. (2011). "Preventive Policing, Surveillance, and European Counter-Terrorism." Criminal Justice Ethics 30(1): 1-22.

Stalcup, M. and C. Hahn (2016). "Cops, cameras, and the policing of ethics." Theoretical Criminology 20(4): 482-501.

Vertegaal, R. and J. S. Shell (2008). "Attentive user interfaces: the surveillance and sousveillance of gazeaware objects." Social Science Information 47(3): 275-298.

Wilson, C., C. Willis, J. K. Hendrikz, R. Le Brocque and N. Bellamy (2010). "Speed cameras for the prevention of road traffic injuries and deaths." Cochrane Database Syst Rev(11): Cd004607. 